\title{
Scottish oral drive needs detailed and funded plans
}

Dentist leaders are calling for specific details on how Scotland's national drive to improve oral health will be funded and achieved.

In January of this year, the Scottish

Government published its Oral Health Improvement Plan (OHIP) ${ }^{1}$ promising steps to prevent poor oral health, cut oral health inequalities and address the needs of the ageing population.

It outlined a new preventive system of care to assess patients based on risk, and address the link between deprivation and ill-health alongside the introduction of personalised care plans which focus on lifestyle choices such as diet, alcohol and smoking, and how these impacted on health.

Specific recommendations included a scheme to meet the needs of the ageing population, enabling suitably skilled practitioners to treat people cared for in their own homes; a Community Challenge Fund of up to $£ 500,000$ in 2018-19 to allow organisations to bid for funding to work in deprived communities and support people to practise better oral health; and to extend the time between dental checks to 24 months for some patients.

As part of the recent announcement by Prime Minister Theresa May of an extra
$£ 20$ billion being injected into the NHS by 2023-24, $£ 2$ billion of additional funding has now been made available for NHS Scotland.

In an open letter ${ }^{2}$ sent to the newly appointed Cabinet Secretary for Health and Sport Jeane Freeman, British Dental Association Scotland urged her to provide some more detail on OHIP with information on planning, timelines and provision of necessary resources.

Chair of the BDA's Scottish Council, Robert Donald, said: 'The Oral Health Improvement Plan sets big aspirations, but provides little detail on funds set aside to pay for them. The promise of extra NHS budget now offers a vital opportunity to secure necessary resources required for implementation.

'Meeting the needs of an ageing population and reducing oral health inequalities in Scotland are vital goals. However we are yet to see details on plans, timescales or resources to achieve them, or indeed any tangible commitment to maintain the financial viability of high street practices during a period of profound change.

'Sadly, instead of needed investment, a focus on 24 month recall intervals feels like a bid to spread a steady state budget too thinly.

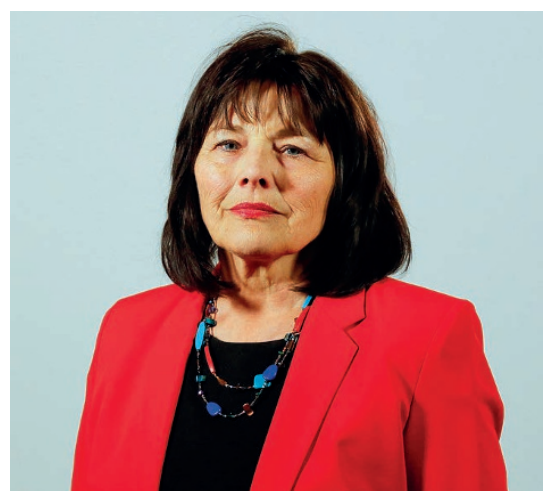

Cabinet Secretary for Health and Sport Jeane Freeman

When oral cancer rates are surging - and early detection is key - the Scottish

Government needs to reconsider. Likewise a change in tack on scale and polish looks like a cost cutting exercise.

'Prevention could reap huge dividends for Scottish patients and taxpayers. The Scottish Government needs to show it is prepared to make an effective investment in oral health.'

1. Scottish Government. Oral Health Improvement Plan (January 2018). http://www.gov.scot/Resource/0053/00530479. pdf (accessed on 18 July 2018).

2. BDA Scotland. Open Letter to Cabinet Secretary for Health and Sport. https://www.bda.org/news-centre/ press-releases/Documents/robert-donald-jeane-freeman-letter-120718.pdf (accessed on 18 July 2018).

\section{Low sugar version of leading milk chocolate bar coming in 2019}

Cadbury has announced it will start selling a lower sugar version of its Dairy Milk bar from 2019 in response to growing calls for sugar reduction in confectionary products.

The company said that a new version of the chocolate bar with $30 \%$ less sugar would be available in the UK from 2019 sold alongside the standard bar.

The decision showed the commitment of Mondelēz International (the company that owns Cadbury) to help towards tackling obesity, including childhood obesity, in the UK, it said.

If the product is successful with consumers, Mondelēz International said it might also apply the same reformulation approach to other Cadbury products.

Other lower sugar versions are being planned for

\section{Dairy} Milk,

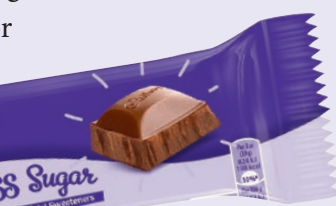

the UK market over the next two years and these include:

- Cadbury Boost+ Protein, which will contain $12 \mathrm{~g}$ of protein per bar and 32\% less sugar than the standard Boost bar

- $30 \%$ less sugar variants of Maynards Bassetts hero products, Wine Gums and Jelly Babies.

Glenn Caton, President, Northern Europe, Mondelēz International said: 'We are working hard to ... help people make informed choices by providing clear nutritional information and labelling, as well as providing more choice by expanding our portion control offerings and improving the nutritional profile of our brands. We believe this strategy is working, with people for example eating less chocolate today than five years ago.'

In August 2016, the Government published Childhood obesity: A plan for action, ${ }^{1}$ and as part of that strategy, Public Health England (PHE) was asked to oversee a sugar reduction programme which challenged all sectors of the food industry to reduce by $20 \%$ the level of sugar in the categories that contribute most to the intakes of children up to 18 years by 2020 . Industry was also challenged to achieve a $5 \%$ reduction in the first year of the programme.

A report ${ }^{2}$ from PHE published in May 2018 looking at progress on this issue said there had been reductions in sugar levels in five out of the eight food categories measured. However, the report said it had not yet seen any reductions in biscuits or chocolate confectionery.

1. HM Government. Childhood Obesity: A plan for Action (August 2016). https://www.gov.uk/government/publications/childhood-obesity-a-plan-for-action/childhoodobesity-a-plan-for-action (accessed on 23 July 2018).

2. Public Health England. Sugar reduction and wider reformulation programme: Report on progress towards the first $5 \%$ reduction and next steps (May 2018). https://assets.publishing.service.gov.uk/government/uploads/system/uploads/attachment_data/ file/709008/Sugar_reduction_progress_report.pdf (accessed on 23 July 2018) 